\title{
LITERATURA E URBANISMO: \\ TRÊS RECORTES NA ESTRUTURA DO RIO DE JANEIRO
}

LITERATURE AND URBANISM:

THREE CUTTINGS IN RIO DE JANEIRO STRUCTURE

LITERATURA Y URBANISMO:

TRES CORTES EN LA ESTRUCTURA DEL RIO DE JANEIRO

Valdemar Valente JUNIOR.

RESUMO:

O presente artigo busca detectar elementos que aprofundem a relação entre literatura e urbanismo em vista das mudancas decorrentes das reformas urbanas no Rio de Janeiro no transcurso do século $X X$. Em sua condição de cidade situada entre o mar e a montanha, o Rio de Janeiro enfrenta problemas referentes à circulação de seus habitantes e à redistribuição de seus espaços. Desse modo, as reformas ao longo do tempo se fazem necessárias. Contudo, há que se pensar no processo de exclusão que delas advém uma vez que aos administradores apenas interessa redefinir espacos e criar condições de acesso às classes superiores banindo os subalternos paras áreas da periferia. Assim, as análises de Cinematógrafo, de João do Rio, Desabrigo, de Antônio Fraga, e Cidade de Deus, de Paulo Lins, trazem o olhar da literatura acerca dessas transformacões.

PALAVRAS-CHAVE:

Reforma urbana; Narrativa; Crise social.

\section{ABSTRACT:}

This article aims to identify elements that deepen the relationship between literature and urbanism in view of the changes resulting from urban reforms in Rio de Janeiro during the twentieth century. As a city located between the sea and the mountain, Rio de Janeiro faces problems regarding the circulation of its inhabitants and the redistribution of their spaces. Thus, reforms over time are necessary. However, one has to think about the process of exclusion that comes from them since administrators are only interested in redefining spaces and creating conditions of access to the upper classes by banning subordinates to areas of the periphery. Thus, the analyzes of Cinematógrafo, by João do Rio, Desabrigo, by Antônio Fraga, and Cidade de Deus, by Paulo Lins, bring the literature on these transformations.

KEYWORDS:

Urban reform; Narrative; Social crisis.

\section{RESUMEN:}

Este artículo busca detectar elementos que profundicen la relación entre la literatura y el urbanismo en vista de los cambios resultantes de las reformas urbanas en Río de Janeiro durante el siglo XX. como ciudad ubicada entre el mar y la montaña, Río de Janeiro enfrenta problemas relacionados con la circulación de sus habitantes y la redistribución de sus espacios. Por lo tanto, las reformas a lo largo del tiempo son necesarias. Sin embargo, hay que pensar sobre el proceso de exclusión que proviene de ellos, ya que los administradores solo están interesados en redefinir espacios y crear condiciones de acceso a las clases altas al prohibir subordinados en los espacios de las chabolas. Así, los análisis de Cinematógrafo, de João do Rio, Desabrigo, de Antônio Fraga y Cidade de Deus, de Paulo Lins, traen el análisis de la literatura sobre estas transformaciones.

PALABRAS CLAVE:

Reforma urbana;

Narrativa; Crisis social. 


\section{INTRODUÇÃO}

A cidade do Rio de Janeiro, por sua condição de metrópole encravada entre o mar e a montanha, sem ter para onde se expandir,

necessita periodicamente da intervenção do poder público no sentido de redefinir parte de seu traçado urbanístico, dotando-a das condições de fluxo entre suas artérias. Nesse sentido, há que se pensar em três dessas intervenções como momentos de redefinição que atingem diretamente o modus vivendi da população em torno das áreas afetadas. Para tanto, pensamos ser procedente recorrer ao processo de urbanização comandado pelo prefeito Pereira Passos, em vista do que representou a abertura da Avenida Central, rebatizada, anos mais tarde, de Avenida Rio Branco, a partir do arrasamento de cortiços e pardieiros insalubres e da expulsão compulsória de seus moradores para os morros em torno do Centro ou para os subúrbios na extensão da linha férrea. Em seguida, a abertura da monumental Avenida Presidente Vargas, pelo prefeito Henrique Dodsworth, implicando na destruição do patrimônio arquitetônico colonial, a exemplo das igrejas de São Pedro dos Clérigos e do Bom Jesus do Calvário e da Praça Onze de Junho, bem

como do saneamento moral que baniu da Zona do Mangue malandros e prostitutas para áreas distantes. Por último, a ação do governador Calos Lacerda dando fim a favelas da Zona sul como Catacumba, Praia do Pinto, Pasmado e Macedo Sobrinho, ao transferir seus moradores para conjuntos habitacionais como Vila Kennedy, Vila Aliança, Vila Kosmos e Cidade de Deus.
Por conta disso, o banimento das populações pobres dos pontos onde gravitam os interesses da classe dominante apresenta-se como tema recorrente nos instantes destacados nas obras de João do Rio, Antônio Fraga e Paulo Lins, escritores separados no tempo que, cada qual a seu modo, buscam colocar em questão as formas do capitalismo em expansão como confronto aos anseios de uma população subalterna, condenada a ocupar subpatamares sociais na hierarquia do acesso a bens materiais e culturais que parecem não Ihes dizer respeito. Nesse sentido, a situação de deslocamento dessas populações resulta nas observações contidas em Cinematógrafo (1909) Desabrigo (1942) e Cidade de Deus (1997), que potencializam um desvio no fulcro de ações que podem repercutir de modo positivo, mas que resultam no afastamento de pobres e marginais para uma espécie de território obscuro, em vista do preconceito e da violência que marcam a relação das instituições governamentais com esses segmentos da sociedade. Há que se pensar, do mesmo modo, que essa relação atende ao interesse absoluto das elites, no que tange à manutenção referente aos espaços de poder que sob qualquer pretexto não podem ser divididos.

A isso corresponde a atuação de João do Rio como escritor de cuja pena nascem formas originais de observação acerca da cidade afetada pelas picaretas da regeneração, quando se impõe a máxima de demolir o antigo para inaugurar - novo. Nesse sentido, sua escrita estabelece uma relação de disparidade entre o requinte da Exposição do Centenário da Abertura dos Portos e suas referências à vida burguesa, na convivência com cinematógrafos e confeitarias, e - submundo marcado pela presença de menores infratores e rinhas de galo, na ambiência da zona portuária e do subúrbio. Assim, se faz importante refletir acerca de que sua obra perpassa seguidamente os diferentes escaninhos da cidade que se transforma por conta das obras da regeneração responsáveis pelo agravamento de uma cisão que não possui meios de retroceder. A fúria devastadora que arrasa os espaços do Centro do Rio de Janeiro corresponde à transformação que irá franqueálos à fruição das elites argentárias e arrivistas que se movem como peças no xadrez da política em sucessivos lances. Por conta disso, Cinematógrafo confirma-se como recorte de época capaz de dar conta da brusca alteração na ordem dos fatos decorrentes das obras de regeneração do Centro.

O momento seguinte a ser detectado resulta da destruição de um patrimônio cultural que diz respeito à abertura da Avenida Presidente Vargas, na ocasião em que os pardieiros do Mangue e da Praça Onze são atingidos por medidas restritivas que resultam no desaparecimento do local onde acontecia o desfile das Escolas de Samba no Carnaval. Esse golpe, em nome do progresso da Capital Federal, representa um ponto de desarticulação da cultura popular, especificamente relacionada ao samba como expressão de um sentimento coletivo que se vê obrigado a reordenar seus mecanismos de atuação. Do mesmo modo, à política de arrasamento do patrimônio público segue-se a perseguição policial dos ele- 
-mentos que fazem desses redutos seus espaços de atuação. Assim, sambistas, malandros, jogadores de chapinha, meretrizes e apontadores do jogo do bicho são criminalizados em nome de uma ordem que se ampara nos horrores da guerra pela via de um regime de exceção. Por esse meio, Desabrigo, novela esquecida por várias décadas, pode se funcionar como retrato escatológico de um período de profundas alterações na vida da cidade.

Por outro lado, o êxito diante do público e da crítica alcançado por Cidade de Deus coloca em questão o deslocamento das populações situadas em favelas da Zona Sul para os conjuntos habitacionais da Zona Oeste, a exemplo da Cidade de Deus, comunidade que pontifica como ponto de partida da relação com o crime organizado, a partir da presença do narcotráfico como braço armado da ação criminosa que passa a ter efeito. Nesse sentido, o conceito de favela, expressão que descreve - Morro da Providência, no Centro do Rio de Janeiro, para onde se dirigem os soldados oriundos da Guerra de Canudos, em função vegetação existente no sertão baiano, passa a fazer referência a qualquer lugar habitado por gente pobre, sejam barracos de madeira e zinco ou conjuntos habitacionais de concreto armado, no alto dos morros ou ao nível do chão. Daí a obra de Paulo Lins vir a ocupar um lugar essencial no que tange à transformação que tem efeito no mapa social da cidade, agravando o debate em torno do que representou o êxodo dos subalternos expulsos das favelas da Zona Sul em direção às áreas distantes dospontos de referência do mercado produtivo.
Nessas condições, há que se pensar acerca das mudanças que se impõem como desafio à geografia do Rio de Janeiro, mas que do mesmo modo interferem no tecido social afetado pela radicalidade dessas mudanças. Os aspectos inerentes aos processos em curso nesses três momentos têm em comum a incapacidade das elites em conviver com quem delas difere, do mesmo modo que essas medidas de profilaxia social não consideram a necessidade de os subalternos ocuparem espaços destinados aos privilegiados, não havendo qualquer acordo de sentido contrário. Assim Cinematógrafo, Desabrigo e Cidade de Deus concorrem como intervenções possíveis, na medida em que João do Rio, Antônio Fraga e Paulo Lins situam-se como escritores que têm acesso direto ao meio de que se utilizam na elaboração de suas respectivas obras. A descrição das imagens da cidade como canteiro de obras tende a elucidar momentos diferentes, mas têm em comum a marca da autoridade dos governantes no que se refere às formas arbitrárias através das quais essas empreitadas se realizam sem que se conte com a opinião da população diretamente atingida.

\section{O PEDREGULHO E A VITRINE}

A cena descrita por João do Rio na crônica "As crianças que matam" pode dar conta da violência relativa aos excluídos que se homiziam na zona portuária. Ao ser ciceroneado por um policial, João do Rio constata a presença de menores armados de facas, portando nas mãos tamancos que Ihes servem do mesmo modo com armas. A proximidade em relação ao cais do porto possibilita ao escritor a observação acerca de uma língua comum referente ao contato dos descendentes de escravos com marinheiros estrangeiros, em uma espécie de argot que Ihes facilita a relação, no que se refere a um diálogo possível. Nesse sentido, as crônicas de Cinematógrafo dão conta da setorização precária dos espaços do Centro, a partir de uma reforma extremamente excludente, no que tange aos anseios dos que se veem preteridos de seus lugares. Do mesmo modo, esse conjunto de crônicas oscila em seu direcionamento, indo dos pontos de exclusão e violência ao ambiente requintado dos pavilhões construídos para receber a Exposição. Diante disso, a via de mão dupla entre a opulência e a pobreza confirma-se como observação das mais preciosas no que diz respeito ao espaço que se abre como conflito sem que para isso haja um termo de conciliação:

Essa volta é justa,
porque no escritor
superficial e brilhante
corriam diversos
filões, alguns curiosos,
alguns desagradáveis
e outros que revelam
um inesperado
observador da miséria,
podendo a seus
momentos denunciar
a sociedade com um
senso dejustiça e uma
coragem lúcida que
não encontramos nos
que se diziam adeptos
ou simpatizantes do
socialismo e do
anarquismo
(CANDIDo, 1982, p.
82)

Pelo que explicitam as crônicas de Cinematógrafo, não existem meios que possam estabelecer um consenso, em vista do aço- 
-damento relativo ao implemento da técnica em um país dependente e atrasado sem que a isso se imponham desencontros. Daí os textos se alternarem dando conta do paradoxo entre o footing de avenida, por entre vitrines coloridas, e as descargas de carvão como expressão do trabalho desumano, na medida em que a luz que ilumina a cidade como um avanço da civilização depende da atuação de homens reduzidos à condição de rebotalhos que obedecem à ordem e à especulação do capital. Nesse sentido, as relações de trabalho, em vista de que há apenas duas décadas a escravidão fora extinta, continuam a atender aos interesses que demandam tarefas aos subalternos. A isso acrescenta-se a atividade de configurar o calçamento de paralelepípedos das ruas por onde passam os elegantes, em contraponto com as ruas de terra batida dos subúrbios onde - esgoto a céu aberto e a ausência de água potável contribuem para a proliferação de várias doenças. Em vista disso, as observações de João do Rio atravessam a cidade em sua geografia da abundância e da pobreza configurada em suas andanças de cronista e jornalista.

Assim, na medida em que os espaços de lazer e cultura se redefinem, tendo como paradigmas a abertura da Avenida Central, por onde passam a circular bens e serviços, há que se pensar na inoperância do poder público no que se refere ao atendimento dos interesses da população dos subúrbios,

precariamente servida pela rede ferroviária. Deve-se pôr em questão uma espécie de estética que estabelece um phatos de dife- -rença entre o que seja o subúrbio em relação à cidade. $\mathrm{Na}$ crônica "O barracão das rinhas", por exemplo, na condição de jornalista, João do Rio desce de um trem na estação de Sampaio, na ocasião em que visita uma rinha de galos. Diante disso, é imperativo pensar-se acerca de um jargão comum aos apostadores a que o escritor confessa não conhecer. Por esse meio, o trânsito nas relações entre diferentes classes sociais se estabelece de modo pleno, uma vez que entre os apostadores encontram-se figuras proeminentes como o poeta Luiz Murat, membro da Academia Brasileira de Letras e - senador Pinheiro Machado, representante máximo do Poder Legislativo. Desse modo, há que se refletir acerca do ambiente da rinha de galos, envolto pelo cheiro de sangue que emana dos animais em combate, onde também se encontram personalidades locais, haja vista a presença de comerciantes endinheirados que do mesmo modo cultivam a paixão pelos galos de briga:

Ora a confeitaria, ora
o botequim, mas
sempre a cidade e a
rua. Nunca a casa. A
casa revela um espaco
regrador por
hierarquias de idade,
sexo e condição. Nada
disso se verifica na
variedade
multitudinária da rua,
onde as diferenças se
diluem ou, até mesmo,
se anulam. (ANTELO,
1989, p. 15)

A relação de proximidade e distanciamento que João do Rio estabelece, em vista do que significam os espaços por onde transita, atende à diretriz de seu trabalho de jornalista ao tempo em que ajuda a definir as regras de convivência diante das posturas municipais que se impõem ao Centro redefinido em sua estrutura e seu diapasão de conduta. A nova ordem, portanto, define vínculos que comprometem o cidadão com relação às práticas que destoam da tolerância do que antes representava a insalubridade como marca da cidade infestada por surtos epidêmicos. Esse tema tantas vezes abordado ao longo da obra de João do Rio concorre como observação recorrente, dando azo à condição inerente ao cotidiano da cidade como uma situação diante da qual não parece haver solução a curto prazo. Nesse aspecto, Cinematógrafo funciona de modo a colocar em questão o contraponto de uma sociedade dividida quanto aos rumos a serem seguidos, uma vez que nesse contexto não se pode visualizar uma opção que atenda à situação decorrente da crise que se abate sobre as camadas populares. A dimensão desse conflito não tem como ser medida em função do que Cinematógrafo representa como possibilidade de observação crítica acerca das obras de regeneração.

Por sua vez, a abertura representada pela Exposição corresponde à tentativa de colocar os principais produtos de exportação do país na vitrine internacional em vista de sua cotação de mercado. Os pavilhões que abrigam esse evento reúnem o que se espera nos termos de uma grã-finagem alçada ao poder por conta da jogatina política que se configura nesse período. Nesse sentido, a imagem do país obedece a interesses que não se apresentam factíveis diante da superficialidade das ações de um governo que se apresenta 
de modo decorativo, obedecendo a uma estética do artifício que segue na direção contrária do que representa o enfrentamento da realidade. 0 enfoque dado à abertura a Avenida Central serve como elemento divergente, se for pensado $O$ que significa $O$ descumprimento de demandas sociais. A pavimentação da principal artéria do Centro mostra-se como ação suficiente e medida ao alcance da sociedade em seu conjunto. Diante disso, Cinematógrafo apresenta-se como coletânea de crônicas nas quais a indignação diante da injustiça se

contrapõe ao entusiasmo de um sistema que investe no futuro, ainda que através de medidas obsoletas. Daí a narrativa de João do Rio efetivar o primado da técnica que tem por base o jornalismo como atividade profissional que se alimenta da rapidez das ações de uma cidade que se desenvolve como cartão-postal do que o poder deseja mostrar ao resto do mundo. No entanto, essa imagem idealiza não faz senão aprofundar o abismo que separa as diferentes camadas da sociedade colocadas em escaninhos opostos, não havendo, a partir das medidas discricionárias de regeneração, a possibilidade de um intercurso entre seus diferentes lugares sociais. Nesse sentido, a crônica de João do Rio concorre para que sejam abordados esses espaços de diferença. Ainda que caiba aos poderosos chafurdar no submundo do vício e da degeneração, aos pobres resta um lugar especifico, marcado pela imobilidade social de onde não se faz possível sair. Diante disso, Cinematógrafo confirmase como obra narrativa que expõe as diferentes máscaras da sociedade carioca, em vista uma República que oscila no caminho a seguir, fracassando em seu resultado final. Isso ocorre por conta de uma sucessão de injustiças que exclui a grande massa do acesso aos prodígios da técnica, banindo-a para as áreas periféricas:

A relação da epública com a cidade só fez, em nosso caso agravar o divórcio entre as duas e a cidadania. Primeiro, por ter a República neutralizado

politicamente a cidade a cidade, impedindo que

autogovernasse e reprimindo a mobilização política da população urbana. A seguir, quando a República, uma vez consolidada, quis fazer da cidade-capital o exemplo de seu poder e de sua pompa, o símbolo, perante a Europa, de seus foros de civilização e progresso (CARVALHO, 1991, p 162)

A capacidade de observação de João do Rio corresponde à urgência por medidas capazes de dotar a Capital Federal das condições de concorrer com as metrópoles do mundo. No entanto, o enfrentamento de situações inerentes à exclusão como regra básica de uma sociedade sob forte dependência do capital externo faz com que a euforia de uma belle époque de feição tropical converta-se no malogro de um projeto que em pouco tempo denunciaria sua condição de obsolescência. Por isso, a distinção entre civilização e barbárie, no sentido da diferença entre patamares sociais, acaba por não manifestar de modo definido a supremacia de uma sobre a outra, uma vez que o sonho de civilização não tem como incorporar os que cronicamente se situam do lado de fora desse processo. A superação do impasse que se impõe como estorvo às pretensões de um país que se pretende moderno sem ter solucionado questões essenciais no tocante ao trabalho e à educação encontra em Cinematógrafo a dimensão de um processo civilizatório a reboque, que se instaura ao acaso, sem a verdadeira dimensão de onde poderia terminar.

\section{MALANDRO EM SINUCA}

O surgimento de Desabrigo pode situar-se como ponto fora da curva, no que tange à ausência de elementos que relacionem o valor dessa novela ao completo desprestígio que pesa sobre seu autor. De fato, Antônio Fraga concorre em condições de extrema desigualdade com os demais escritores de sua geração. Expulso de casa ainda adolescente, convive com a exclusão e a marginalidade nos ambientes do crime e da prostituição, na Lapa, no Mangue e no Estácio. A convivência com jogadores de sinuca, passadores de entorpecentes e agentes do sexo faz dele alguém para quem o cotidiano apresenta-se em sucessivos capítulos, cada qual sugerindo uma surpresa a ser vivida ou um drama a ser contornado. Por conta disso, Desabrigo reitera o lugar do escritor que se nutre se sensações provisórias em suas andanças pelos caminhos tortuosos das ruas onde aprende a soletrar na cartilha da sobrevivência. Assim, há que se refletir acerca de que Desabrigo se situa como voz em surdina 
dos malandros e prostitutas que vivem no Mangue, sofrendo duros revezes em decorrência da política que passa a ter efeito com a higienização moral da Capital Federal:

O ato de escrever para Antônio Fraga é um mergulho em si mesmo, no mundo periférico que os acadêmicos tanto vilipendiam. Escrever, também, é orgasmar por palavras sobre a sociedade que o baniu e oferecer-lhe, como troco, a fertilização da linguagem. O naco de sujeira e violência, que, às vezes, permeia sua prosa, ilumina o mundo interior, fustiga o subconsciente, provoca tal impacto no leitor que ele abandona o livro ou parte para a aventura. (SILVA, 1999, p. 9)

A partir dessas medidas, os velhos malandros desaparecem, em vista do confronto com a polícia, quando não, os que sobrevivem se retiram para os subúrbios, na medida em que não há espaços possíveis à sobrevivência em seu antigo habitat. Além disso, deve-se considerar como fator de extrema relevância a abertura da Avenida Presidente Vargas como via pública que visa a ampliação do acesso entre a Zona Norte e o Centro, o que concorre para o desaparecimento da Praça Onze. $O$ corte vertical promovido, corresponde ao sentido do que Antônio Fraga confirma em Desabrigo como espécie de narrativa da exclusão a preencher os espaços vazios deixados pelo desaparecimento de personagens condenados a se evadirem. A decadência dos bares, nas imediações do Mangue, dá conta da operação que rasga de um lado ao outro o tecido urbano, promovendo o desaparecimento de locais que se constituíam em símbolos da cultura carioca, a exemplo da Praça Onze, que desaparece, como afirma a letra de um samba de enorme sucesso nesse tempo. Do mesmo modo, muitos malandros são confinados em prisões, retirados de circulação por força de uma ordem coercitiva que pouco a pouco os elimina.

A questão crucial que se apresenta em Desabrigo dá conta do silêncio de décadas sobre uma obra que busca desarticular o discurso da tradição, na medida em que inviabiliza a linearidade referente aos escritores a que Antônio Fraga chama de anatoles. Nesse sentido, a novela opta pelo emprego de uma linguagem que se coaduna à voz dos que habitam o espaço que the serve como cenário de ação. Daí a narrativa tentar reconstruir o que se perdeu, buscando recuperar em meio aos destroços da ação predatória a memória de um tempo em que os malandros enganavam os otários escondendo a bolinha, no jogo de chapinha, ou as prostitutas subtraíam os pertences de seus clientes. A isso se interpõe a máquina produtiva que concorre para a evacuação desses espaços, na intenção de abrir frentes de negócio junto ao mercado imobiliário que especula valores de compra e venda. $O$ arrasamento de vários quarteirões provocaria fraturas que jamais tornariam a se consolidar, em vista das ruas cortadas ao meio ou condenadas ao desaparecimento. Assim, Desabrigo pontua a reafirmação de um passado recente que antecede ao rigor de um sistema tentacular que criminaliza as práticas consideradas como desviantes em nome de uma ordem higienista e moralizante:

Imagine escrever um livro sobre o Mangue, dando voz a seus personagens e mitos, trazendo para a literatura o mau comportamento e a linguagem pouco apurada, sem rodeios e impregnada de gírias, daquela gente. Um livro que denunciasse aquele mundo de dentro para fora, rico em situações e marcado pela violência, sem se preocupar com os puristas de estilo, numa época de acentuada repressão e beletrismo. (MELLO, 2009, p. 176)

Os deslocamentos do Mangue em direção ao Estácio, à Lapa e à Avenida Rio Branco, onde se situa O Café Nice, dizem respeito aos expedientes em torno da negociação de sambas, ao jogo e à prostituição, incluindo-se nesse circuito a via de mão dupla que se estabelece em relação à zona portuária, através do contato com marinheiros e contrabandistas. Assim, a proposta contida em Desabrigo amplia a possibilidade de observação que tem no Mangue um ponto de partida, na medida em que dirige sua observação a espaços contíguos na busca por relações de proximidade e preservação de um modus vivendi importante à existência de um determinado grupo social. Por isso, Antônio Fraga, em sua relação com o submundo do crime e do vício, estabelece em Desabrigo mecanismos de consolidação de uma cultura a 
ser preservada, mesmo em condições desiguais e sob forte pressão externa. $\bigcirc$ corte efetuado na região central da cidade concorre para que se modifique a geografia de uma zona boêmia que se transfere para bairros litorâneos como Copacabana e Ipanema, condenando-a ao ostracismo e a

abandono, uma vez que o Mangue passa a ser um esconderijo de infratores.

A abertura da Avenida Presidente Vargas, por sua vez, concorre para o desaparecimento da Praça Onze, atingindo as manifestações em torno do samba, no que isso se mostra como expressão cultural de marginais. Desse modo, o preconceito social alia-se à justificativa pautada na necessidade da abertura de espaços para que a grande avenida tenha seu sentido de existência. $\bigcirc$ movimento contrário corresponde à circulação de diferentes atores da cena urbana obrigados a se retirarem sob pena de sucumbirem à ação repressora. Assim, os tentáculos desse sistema podem funcionar como pontos-chave à fatura dessa novela, expressando o desconforto social que se abate sobre a Capital Federal no período que prenuncia a presença brasileira na Segunda Guerra Mundial. Nesse sentido, Desabrigo reafirma sua condição de escrita que se serve do espaço de vivências de seu autor ao desenrolar o carretel da memória acerca de fatos que se coadunam à ficção como em um jogo de anteparos entre o real e verossímil. De todo modo, não há como deixar de fora sua participação como termo que agrava a relação entre a literatura e o universo dos excluídos.

Diante disso, evidencia-se um processo de marginalização que se estende das práticas criminalizadas a aspectos de uma linguagem também discriminada, a exemplo do samba como gênero musical comum a malandros e jogadores que passam a ter nele um ponto de referência. Nesse sentido, há que se pensar que a higienização que atinge a Lapa e o Mangue determina um alinhamento no que tange à malandragem exaltada nas letras dos sambas, a partir do estímulo à regeneração pelo trabalho, o que ocorre apenas como uma estratégia provisória. Por conta disso, Desabrigo apodera-se como propriedade de um discurso que contraria a ordem imposta pelo arrasamento da Praça Onze, concorrendo para que a linguagem marginal que se desenvolve nas letras de samba seja banida como mais um sintoma da higienização que se efetiva. Condenados à perseguição policial que passa a vigorar com o Estado Novo, e vistos como desocupados, os compositores são compulsoriamente levados a uma profissionalização que não se faz representar a partir das regras que o Estado determina, uma vez que a remuneração por esse trabalho continua sendo exígua. A isso Antônio Fraga se remete, uma vez que sua novela compreende a abrangência social do que representa a vida no Mangue e em seus lugares adjacentes:

Na literatura brasileira, nessa época, não são comuns textos que reproduzam a fala, os gestos e a vida da marginália carioca; há, no entanto

compositores

populares, como Geraldo Pereira, Noel Rosa e Wilson Batista, entre outros, cuja obras traduzem ação e fala dos atores sociais identificados com o universo dos excluídos. Nas páginas das obras de Fraga, circulam termos e expressões de um texto pulsante falado e composto de forma coletiva na vida da cidade do Rio de Janeiro e de seus locais periféricos, populares - como Mangue e a Lapa. (SILVA, 2009, p. 9).

Os disparates relativos a uma sociedade excludente concorrem para que Desabrigo evidencie os meios de sobrevivência dos que habitam a semi-sombra de um mundo impiedoso. Assim, a destruição dos espaços públicos que reitera o progresso e a velocidade das ações concorre para o aniquilamento da ambiência social dos que neles constituem relações que se deterioram. Em vista do que representa a força do capital que ergue e destrói, transformando em ruina o que nem sequer encontra tempo suficiente para exercer sua função, Desabrigo observa os trâmites de um processo diante do qual não há remissão. $O$ ciclo predatório que se verifica em espaços de tempo cada vez mais curtos atinge o Mangue e a Praça Onze, inviabilizando determinadas práticas que tendem a se reorganizar a partir de valores que diferem de sua concepção. Assim, a originalidade de um mundo que se mostra de modo pessoal e intransferivel, no que tange a sua relação com as coisas mais simples, no entorno de uma realidade que segue o caminho da destruição, inviabiliza qualquer proposta que tenha a a originalidade e a inspiração como regras. 


\section{ENTRE O ASFALTO E A FAVELA}

A cisão que se verifica entre as populações do Rio de Janeiro, no que se refere aos espaços de convivência comum que a cada dia desaparecem, diz respeito à ação perpetrada por determinados governantes no sentido de condenar os mais pobres a um confinamento sem qualquer possibilidade de intercâmbio de suas experiências. Isso decorre da estigmatização que toma conta das elites em defesa de suas posições de classe, não havendo de sua parte como conferir qualquer mérito aos que não Ihes ombreiam na mesma condição social. Disso decorre uma série de posturas no sentido de alijar os pobres dos espaços de excelência de consumo e convivência onde devem apenas concorrer na condição de empregados e prestadores de serviço. A essa postura acrescenta-se um esforço que visa a criação de bairros-dormitórios na periferia da cidade, a exemplo da Cidade de Deus, conjunto habitacional que em sua origem visa abrigar a população de morros e favelas atingida pelas enchentes que tiveram lugar ao longo da década de 1960. As políticas de remoção que tiveram início sob - comando do governador Carlos Lacerda estendem-se ao período posterior ao golpe militar, em decorrência da ação antidemocrática que passa a ter efeito:

No mercado brasileiro surgiu, nos últimos anos, um outro fenômeno que, em intenso diálogo com as novas formas de realismo, coloca o contato com a realidade atual brasileira como foco principal. Trata-se aqui, de uma literatura que, sem abrir mão da verve comercial, procura refletir os aspectos mais inumanos marginalizados da realidade social brasileira (SCHOLLHAMMER, 2009, p. 98).

Em vista disso, Paulo Lins observa em Cidade de Deus a dimensão de um problema que se transfere da Zona Sul para regiões de acentuada vocação rural, a partir de onde se define - conceito de neofavela, que corresponde à participação do narcotráfico como expressão que legitima sua atividade nesses locais. Assim, há que se destacar em Cidade de Deus um recorte específico do que parece ser o escopo de Paulo Lins ao detectar o ponto de partida de uma ação no sentido da drástica mudança no mapa social da cidade orquestrada e executada pelo governo. Por essa via, as casas construídas em um lugar ameno, longe da agitação do Centro e dos bairros da Zona Sul, em um tempo relativamente curto convertem-se em redutos de pobreza e exclusão, contrariando o que seria o ideal da casa própria em um espaço de convivência pacífica. A divisão que se verifica na tentativa frustrada de se construir uma cidade dentro da própria cidade atende aos que o governo carioca considera como situação que não se justifica na simples remoção, tampouco resulta no atendimento de demandas que não passem por esse caminho. O redimensionamento da vida pessoal dos que se convertem em personagens de Cidade de Deus assume um lugar inusitado inerente ao ideário dos moradores do conjunto habitacional que voltam a condição de favelados.

Nesse contexto, o narcotráfico, aliado à ausência de medidas do poder público, concorre para que a Cidade de Deus do romance reitere a condição de conjunto habitacional afetado pela política de recessão que aprofunda a crise social do país. As partes envolvidas na dispersão que se verifica com essa brusca mudança de habitat obrigam a população da Cidade de Deus a reordenar sua posição na sociedade, em vista de um modelo de convivência que implica no estreitamento de seu contato com as facções criminosas que se aperfeiçoam, na medida em que a repressão ao crime também se amplia em seus modelos de atuação. Nesse sentido, o deslocamento dessa população de um extremo ao outro a cidade, mais que se consignar em prêmio, diante de uma possibilidade de fruição da vida e suas condições de bemestar, converte-se em purgatório, o que contraria seu próprio nome, em vista dos seguidos confrontos entre policiais e traficantes. Assim, a visão do que Paulo Lins transmite em seu romance corresponde em sua integridade ao estado de abandono com que os moradores da Cidade de Deus convivem desde que foram compulsoriamente transferidos das favelas da Zona sul afetadas pelas chuvas de verão.

Desse processo decorre o florescimento de sucessivas obras narrativas que, a exemplo de Cidade de Deus, concorrem para que a relação entre poderosos e excluídos seja delimitada, uma vez que em um determinado instante passa a prevalecer a voz dos subalternos como uma referência de escrita literária. O ponto crucial da discriminação 
empurra para os subúrbios e subáreas sem prestígio as populações que antes conviviam com os moradores das áreas nobres. Daí o desejo de viver na proximidade dos locais de influência, no que se refere às oportunidades de trabalho e à circulação de bens, parece uma condição exclusiva dos poderosos. Aos pobres restariam os conjuntos habitacionais onde se faz possivel uma convivência comum que não sirva de estorvo aos potentados. Nesse sentido, o romance de Paulo Lins contextualiza o lugar da diferença como uma espécie de abordagem inaugural no que se refere ao que passa a ter efeito como índice de observação entre narrativa e realidade social. $\bigcirc$ contexto em que Cidade de Deus foi concebida patenteia a condição dos oprimidos em seu desejo de superar sua própria condição:

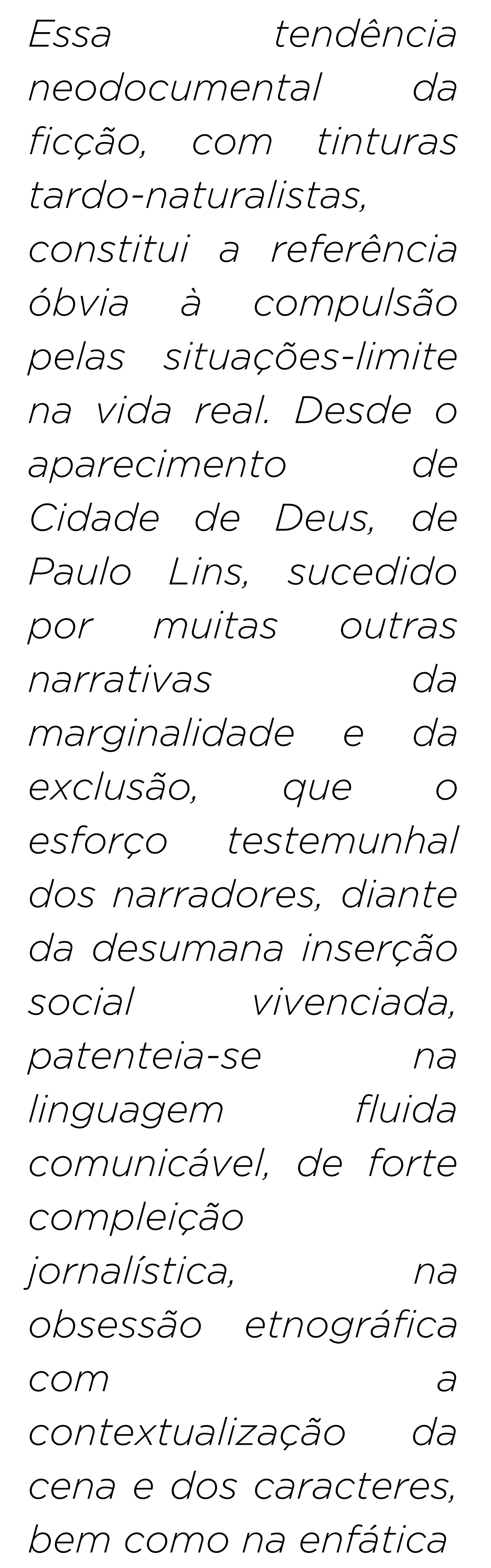

a objetivação da violência, em precisos recortes de extremos da torpeza humana. (DIAS, 2008. p. 30)

A dimensão crítica do que Cidade de Deus assume estende-se do livro ao cinema e à televisão, concorrendo para que a discussão em seu entorno delimite um choque brutal decorrente da manifestação da violência em diferentes níveis. $\bigcirc$ agravamento das questões que se agudizam em sequência, por conta das condições de sobrevivência de suas personagens, alia-se à demanda de violência dos confrontos entre policiais e traficantes nos espaços que deveriam servir apenas como moradia. Desse modo, a transferência imposta acaba por não resolver a situação decorrente da presença de favelas nas áreas nobres da cidade, apenas concorrendo para mudar as favelas de um local para o outro. A dinâmica que se impõe à nova ordem dos fatos encontra no romance de Paulo Lins um elemento referencial, no que se refere à forma através da qual Cidade de Deus consegue trazer para o público leitor a configuração crítica de uma espécie de lugar incomum, na medida em que a figura do bom malandro converte-se no narcotraficante amparado pela dinâmica relativa aos entorpecentes como mais um produto oferecido pelo mercado:

Para indicar os novos tempos, o autor fala em "neofavela", por oposição em acepcão antiga, que foi reformada pela guerra entre os traficantes de droga e pela correspondente violência e corrupcão da polícia. É esse o
- processo que o romance recria, numa escala numerosa, com algo de enciclopédia, que lembra as grandes produções do cinema sobre o gangsterismo. (SCHWARZ, 1999, p. 163)

O obstáculo que se apresenta como termo impeditivo à confirmação da Cidade de Deus como polo de prosperidade corresponde a um projeto que se mostra desviante desde seu início, uma vez que se impõe a retirada da população de uma área para a outra sem nenhum outro argumento senão o incômodo das elites em relação aos pobres. Desse modo, observa-se apenas uma postura eivada de preconceito hegemônico que não se referencia senão na diferença de classes. $O$ conjunto de medidas que cria as cidades-dormitórios inviabiliza a sequência do que seria a existência harmoniosa em um mesmo lugar, uma vez que o narcotráfico e seu imperativo de violência acaba por estorvar qualquer medida que possa impulsionar o crescimento social do conjunto habitacional que se transforma em favela. Em vista disso, Paulo Lins traduz para o plano da ficção a Cidade de Deus que imita a realidade em seu limite extremo, trazendo à tona da narrativa o que de fato parece irmanar-se a uma realidade absolutamente brutal. Daí o propósito embutido na investida oficial tende ao malogro, integrando-se a uma proposta que por si mesma não parece sequer ter nascido.

Assim, a reversão do que se mostra como solução compensatória à ineficiência do sistema concorre para que Cidade de Deus pontifique como expressão de um denuncismo que foge ao 25 
ao espírito idealizador da favela como local onde as flores brotam no lodo e as estrelas se refletem na sujeira. O que se desenvolve ao longo da narrativa induz à crença de que a falta de oportunidades sociais funciona como um obstáculo ao livre desenvolvimento da potencialidade humana em uma cidade por onde Deus parece nunca ter passado. Por isso, a visão maniqueísta da favela esplendorosa com seus barracões de zinco, que desperta para o trabalho com o apito do trem, deixa de fazer qualquer sentido, uma vez que o som das armas de alto calibre passa a ser uma espécie de trilha sonora. A condição inerente ao inevitável impasse que se impõe em vista da derrota de sucessivos modelos assume o contorno de uma situação insolúvel, na medida em que o livro, o filme e o seriado da televisão não se mostram suficientes para que a eles se agregue qualquer perspectiva de mudança.

\section{CONSIDERAÇÕES FINAIS}

A relação entre literatura e urbanismo apresenta-se de modo a fundamentar as mudanças que se impõem sobre o tecido social da cidade. Por essa via, os três recortes apresentados dão conta da visão que cada um desses escritores desenvolve acerca do que a cidade representa no imaginário e na realidade dos que nela habitam. João do Rio, Antônio Fraga e Paulo Lins são mais que três escritores cariocas, a medida em que cada qual a seu modo aprofunda uma via de observação que passaria despercebida ao olhar comum. Nesse sentido, Cinematografo, Desabrigo e Cidade de Deus cumprem o papel de se inscreverem de modo definitivo na vida da cidade, a partir de uma interferência que recruta os setores sociais de
protagonistas de seus respectivos dramas. Mais ainda, as obras arroladas diferem do conjunto das que se referem ao Rio de Janeiro apenas pelo viés relativos às suas belezas naturais e ao espírito festivo e acolhedor de seu povo. Assim, uma outra cidade parece existir dentro daquela Que acolhe visitantes de várias as partes do mundo.

Assim, o impacto decorrente das diferentes obras impostas como mudanças fundamentais à estrutura urbana da cidade serve de motivo para que essa investida não se perca no tempo, uma vez que a ação desses escritores traduz para o plano da ficção a realidade que se impõe. Os três recortes efetuados, ainda que se separem no tempo, têm em comum a divisão de classes que delimita territórios exclusivos à supressão de seus interesses. Daí a ocupação desses espaços representar um crime sem perdão, uma vez que, do ponto de vista das elites, a convivência com os subalternos deve ser estabelecida apenas pelas relações de trabalho e prestação de serviços. Diante desse impasse, cabe aos autores em questão redefinirem 0 espaço social da cidade tendo em vista uma afirmação que corrobore com a luta dos que perdem seus lugares de pertencimento na luta diária pela sobrevivência.

\section{REFERENNCIAS}

ANTELO, Raúl. (1989). João do Rio: o dândi e a especulação. Taurus, Timbre.

\section{CANDIDO, Antonio. (1992).}

Teresina etc. Rio de Janeiro: Paz e Terra, 1992.
CARVALHO, José Murilo de. (1991). Os bestializados: o Rio de Janeiro e a República que não foi. São Paulo: Companha das Letras.

\section{DIAS, Ângela Maria. (2008).}

"Cenas da crueldade: ficção e experiência urbana". In: DALCASTAGNË, Regina. (Org.). Ver e imaginar o outro: alteridade, desigualdade, violência na literatura brasileira. São Paulo: Editora Horizonte, p. $27-40$

FRAGA, Antônio. Desabrigo. (1995). Rio de Janeiro: Secretaria Municipal de Cultura.

LINS, Paulo. Cidade de Deus. (1997). São Paulo: Companhia das Letras.

MEllo, Maria Amélia. (2009). "Um autor maldito. Ou o Joyce do Mangue". In: FRAGA,

Antônio. Desabrigo e outras narrativas. Rio de Janeiro: José Olympio, p. 175-178

\section{RIO, João do. Cinematógrafo.} (2009). Rio de Janeiro: Academia Brasileira de Letras.

SCHOLLHAMMER, Karl Erik. (2009). Ficção brasileira contemporânea. Rio de Janeiro: Civilização Brasileira.

SCHWARZ, Roberto. (1999). Sequências brasileiras. São Paulo: Companhia das Letras, 1999.

SILVA, Maria Célia Barbosa Reis da. (2009). "Desabrigo:

marquise de outras narrativas". In: FRAGA, Antônio. Desabrigo e outras narrativas. Rio de Janeiro: José Olympio, p. 8-17.

\section{(1999). "Prefácio}

marginal". In: FRAGA, Antônio Desabrigo e outros trecos. Rio de Janeiro: Relume Dumará, $p$. 7-12. 
Recebido em 22 out 2019 | Aprovado em 01 dez 2019

Valdemar Valente JUNIOR

Doutor em Ciência da Literatura pela UFRJ. Pós-Doutor em Literatura Brasileira pela UERJ. Professor do Curo de Pós-Graduação em Letras da Universidade Estácio de Sá.

E-mail: valdemarvalente@gmail.com 